\title{
Dispensing of Potentially Harmful Prescription Drugs in 1.8 Million Pregnant Women in France: A Nationwide Study Based on Two Risk Classification Systems
}

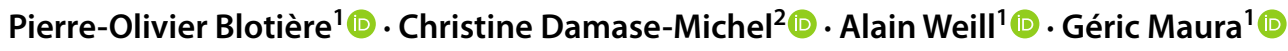

Accepted: 30 August 2021 / Published online: 6 October 2021

(c) The Author(s) 2021

\begin{abstract}
Introduction Nationwide prevalence of potentially harmful drug prescribing during pregnancy is unknown in France, and several risk classification systems (RCS) exist to guide prescribers.

Objective The aim of this study was to estimate the nationwide prevalence of potentially harmful drug prescribing during pregnancy in France and to describe maternal characteristics associated with this prescription.

Methods This drug utilisation study, conducted on the French health databases (67 million beneficiaries), included all pregnancies beginning in 2016-2017, regardless of pregnancy outcome. Potentially harmful drug prescribing was defined as at least one reimbursement during pregnancy of Swedish RCS category D drugs, Australian RCS category D/X drugs, or contraindicated drugs in France for drugs not listed in these two RCSs. Maternal characteristics associated with potentially harmful drug prescribing were described using a univariate logistic regression analysis.

Results Among the 1,844,447 pregnant women identified, the prevalence of potentially harmful drug prescribing was higher according to the Australian RCS (3.9\%) than according to the Swedish RCS (2.2\%), with good agreement between the two RCSs (Kappa $=0.81$ [0.74-0.87]). This prevalence increased to $9.2 \%$ and 6.9\%, respectively, when considering contraindications in France. Prescribing of teratogenic drugs, including retinoids and valproate, was highest during the first trimester, whereas prescribing of foetotoxic drugs decreased after the first trimester but remained high for nonsteroidal antiinflammatory drugs $(N=10,021)$. In women with no chronic diseases, polymedication (five or more drugs) was the strongest maternal characteristic associated with potentially harmful drug prescribing in both RCSs.

Conclusions Potentially harmful drug prescribing during pregnancy is not uncommon in France. This study supports the comparative analysis of RCS to assess potentially harmful drug prescribing in claims databases.
\end{abstract}

\section{Introduction}

The recent valproate crisis in Europe [1], and especially in France, has increased the need for studies investigating potentially harmful drug prescribing during pregnancy in order to establish priorities for pregnancy safety research; however, drug safety during pregnancy can be difficult to assess and this assessment must be updated when new data

Pierre-Olivier Blotière

poblotiere@gmail.com

1 French National Health Insurance (Caisse Nationale de l'Assurance Maladie/Cnam), 50 avenue du Pr. André Lemierre, 75986 Paris Cedex 20, France

2 Pharmacologie Médicale, Faculté de Médecine, Université de Toulouse UPS, Inserm CERPOP, CHU, Toulouse, France become available. To guide both health care professionals and women in the prescribing/use of drugs during pregnancy, various risk classification systems have therefore been developed to classify drugs into risk groups according to their foetal safety. Three classification systems, based on data from human and animal studies, are mainly used [2]: (1) the US FDA system, abandoned in 2015 and replaced by a narrative structure for pregnancy labelling in order to more clearly distinguish different degrees of foetal risk and to facilitate informed prescribing decisions and patient counselling [3]; (2) the Australian Therapeutic Goods Administration system [4]; and (3) the Swedish catalogue of registered pharmaceutical specialties system [5]. No such classification is available in France, where drug prescribing during pregnancy is frequent $[6,7]$ and is higher than in other countries [2]. However, the French Reference Centre for Teratogenic Agents (Centre de référence sur les agents 


\section{Key Points}

Based on data for nearly 2 million pregnancies and using two risk classification systems, this study provides the first nationwide prevalence of potentially harmful drug prescribing in France, i.e. up to $9.2 \%$, regardless of pregnancy outcome.

A high prevalence of nonsteroidal anti-inflammatory drug (NSAID) prescribing was observed after the first trimester of pregnancy.

Several groups of pregnant women who might benefit the most from prepregnancy counselling were identified, including women with chronic diseases, polymedicated women, and women of younger age or deprived.

This study supports the comparative analysis of updated risk classification systems as a convenient tool to assess potentially harmful drug prescribing during pregnancy in studies based on health care databases.

tératogènes chez la femme enceinte [CRAT]) website provides freely available, reliable, evidence-based, and accurate information about the use of medicines in pregnancy to guide prescribers [8], as has also been developed in other countries, such as the website developed by the UK Teratology Information Service [9].

Based on these three risk classification systems, previous studies have reported large variations in the prevalence of potentially harmful drug prescribing during pregnancy, ranging from 1 to $21 \%$ [2]. These variations could be explained by not only the use of different risk groups to define a drug as potentially harmful but also by differences in terms of risk category allocation for the same drug across these three systems [10]. In France, few studies on potentially harmful drug prescribing during pregnancy have been published, most of which were based on regional surveys dating back to the 1990s [11-13], while two more recent studies, based on a sample of the French population, assessed the use of few specific potentially harmful drugs [6,7]. The current use of potentially harmful drugs during pregnancy at a national level in France therefore remains largely unknown and has never been assessed by using risk classification systems. The maternal factors associated with potentially harmful drug prescribing have also never been reported in France and rarely in Europe [14].

We therefore investigated potentially harmful drug prescribing during pregnancy in France using both the Swedish and Australian risk classification systems, to account for potential differences between these two systems and to allow international comparisons, and described maternal characteristics associated with this prescribing. This study was based on the French healthcare databases, allowing nationwide assessment of potentially harmful drug prescribing during pregnancy.

\section{Methods}

\subsection{Data Sources}

In France, national health insurance (Assurance Maladie) provides mandatory health insurance cover for the entire population living in France; all individuals are affiliated from birth or immigration until death or emigration, irrespective of healthcare provider, age, socioeconomic status or retirement status. The corresponding French national health database (Système national des données de santé [SNDS]) therefore covers $99 \%$ of the 67 million people living in France [15] and consists of three nationwide datasets linked by a unique patient identifier: the French national health insurance database, the French hospital discharge database, and the national death registry. The health insurance database contains all individualised and anonymous health care claims reimbursed by French National Health Insurance, as well as demographic and socioeconomic data. In particular, it contains all prescription drugs dispensed by community or hospital pharmacies to outpatients and reimbursed by Assurance Maladie, which are coded according to the Anatomical Therapeutic Chemical (ATC) classification, as well as medical procedures, which are coded according to the French medical classification of clinical procedures (Classification commune des actes médicaux [CCAM]). The hospital discharge database provides detailed medical information on all admissions to public and private hospitals in France, including discharge diagnosis International Classification of Diseases, Tenth Revision (ICD-10) codes, medical procedures coded according to the CCAM, and expensive drugs administered in hospital, which have to be invoiced in addition to the stay.

This linkage has previously been used to conduct largescale studies on drug use and safety during pregnancy [16-18].

\subsection{Study Design and Population}

In this drug utilisation study, all pregnancies starting between January 2016 and December 2017 were eligible for inclusion regardless of the outcome. The pregnancy outcomes considered were live birth, stillbirth, induced abortion (elective and therapeutic), spontaneous abortion, ectopic pregnancy and hydatidiform mole or other abnormal products of conception (e.g., blighted ovum, non-hydatidiform mole or early foetal death with retention of the dead foetus). 
These pregnancies were identified by using a published algorithm based on discharge diagnoses and medical procedures indicative of completion of pregnancy [19] (electronic supplementary material [ESM] Table 1). The procedure date, when available, or admission date, was used as the pregnancy outcome date. The pregnancy start date was calculated from this outcome date and gestational age for all outcomes except for outpatient medical abortion, for which gestational age was not available and was considered to be 6 weeks [19], corresponding to the median gestational age for outpatient medical abortions in a French survey. When a woman had several pregnancies during the study period, all pregnancies were considered.

The mother had to have at least one health care reimbursement by any mandatory health insurance scheme during the 12-month period before the trimester preceding pregnancy to ensure comprehensive assessment of drug use from the trimester preceding pregnancy until the end of pregnancy.

\subsection{Exposure}

A drug was considered to be prescribed to a pregnant woman when she had been reimbursed for this drug at least once between the estimated first day of pregnancy to the estimated last day of pregnancy. In France, chronic medication dispensing usually cannot exceed a 30-day supply. All reimbursed prescription drugs were taken into account except for homeopathic medicines, for which no risk classification exists, misoprostol (Cytotec ${ }^{\circledR}$, Pfizer, Paris; indicated for the healing of duodenal ulcer and gastric ulcer or for the prophylaxis of nonsteroidal anti-inflammatory drug (NSAID)-induced ulcers, withdrawn from the market on 1 March 2018) used off-label to induce abortion in France, the mifepristone/misoprostol combination specifically reimbursed to induce elective abortion (see pregnancy outcomes in ESM Table 1), and hormones, including contraceptives and drugs indicated for fertility disorders, for which available evidence suggests that the potential for foetal harm is unlikely [20-23]. Furthermore, regarding contraceptives, only first-generation (norethisteronecontaining pills) or second-generation (levonorgestrel- or norgestrel-containing pills) combined oral contraceptives and certain pills containing desogestrel are reimbursed in France.

All excluded drugs and their ATC classes are indicated in ESM Table 2. The term 'drug' is used throughout the manuscript as a synonym for the 5th-level ATC class.

For pregnancies resulting in a live birth, the gestation period was divided into three 90-day intervals corresponding to the three trimesters of pregnancy: days 0-90 (first trimester), days 91-181 (second trimester) and day 182 until delivery (third trimester).

\subsection{Outcome}

The outcome was the prevalence of potentially harmful drug prescribing during pregnancy.

Each drug reimbursed during pregnancy was classified according to its foetal safety. Two risk classification systems were used-the Swedish and Australian risk classification systems. These two classification systems are similar except that, in addition to categories A, B1, B2, B3, C and D, the Australian system uses a category $\mathrm{X}$ for drugs with the highest risk of causing permanent damage to the foetus. The definitions of these categories are presented in ESM Table 3. Data from the French Summary of Product Characteristics (SmPCs), provided by the French Ministry of Health and available online [24], were also reviewed.

Two definitions were used to define potentially harmful drugs during pregnancy: (1) category $\mathrm{D}$ drugs according to the Swedish system, or category D or X drugs according to the Australian system (Table 1); and (2) drugs not listed in the Swedish or Australian systems and contraindicated in the French SmPCs, in addition to the potentially harmful drugs identified by using definition 1 . A drug was considered to be contraindicated in the French SmPCs when pregnancy was mentioned in the 'Contraindication' section, or when the 'Fertility, pregnancy and lactation' section stated that the drug must not be used during pregnancy. Labelling of the contraindications in the French SmPCs is based on human and animal data rather than a lack of evidence, according to the European guidelines on risk assessment of drugs on human reproduction [25].

Details on the algorithm used to classify drugs according to their foetal safety are presented in ESM Table 4.

\subsection{Statistical Analysis}

All results are reported separately for the Swedish and Australian risk classification systems.

The prevalence of potentially harmful drug prescribing during pregnancy was defined as the number of pregnancies with a reimbursement for a potentially harmful drug divided by the number of pregnancies reported in the study population and expressed as a percentage. Prevalence rates were also stratified by pregnancy outcome and by trimester of pregnancy for live births, and detailed for each potentially harmful drug. For the calculation of prevalence rates in the second or third trimester, only pregnancies lasting beyond the first or second trimester, respectively, were considered in the denominator.

Two sensitivity analyses were conducted. To define outcome, potentially harmful drug prescribing during pregnancy was assessed by pooling categories $\mathrm{C}$ and $\mathrm{D} / \mathrm{X}$, and also by pooling categories B3, C and D/X (see ESM Table 3 for the definitions of these risk categories). To define 
Table 1 Definition of potentially harmful drugs according to the Swedish and Australian risk categories D and D/X for prescribing medicines in pregnancy

\begin{tabular}{lll}
\hline Swedish classification & Australian classification \\
\hline $\mathrm{D}$ & $\begin{array}{l}\text { Drugs which, in humans, have caused or may be expected to cause an increased } \\
\text { frequency of foetal malformations or other permanent damage. This category } \\
\text { includes drugs with primarily teratogenic effects. If the drug also has negative } \\
\text { pharmacological effects that can directly or indirectly result in adverse effects } \\
\text { on the foetus, this is also stated. }\end{array}$ & $\begin{array}{l}\text { Drugs which have caused, are suspected to } \\
\text { have caused, or may be expected to cause, } \\
\text { an increased incidence of human foetal } \\
\text { malformations or irreversible damage. These } \\
\text { drugs may also have adverse pharmacologi- } \\
\text { cal effects. Accompanying texts should be } \\
\text { consulted for further details. } \\
\text { X }\end{array}$ \\
& $\begin{array}{l}\text { Drugs which have such a high risk of causing } \\
\text { permanent damage to the foetus that they } \\
\text { should not be used in pregnancy or when } \\
\text { there is a possibility of pregnancy. }\end{array}$ \\
\hline
\end{tabular}

exposure, the reimbursement window was extended to the 90-day period before pregnancy.

To assess potential differences in risk category allocation (categories D or D/X versus other categories) of the drugs prescribed in the study population, Cohen's Kappa coefficient was calculated to assess the agreement between the two risk classification systems after restriction to ATC drugs present in both systems. The specialty (hospital practitioner, general practitioner, private specialists) of physicians prescribing potentially harmful drugs were also reported.

To identify subgroups of women who were more likely to be prescribed potentially harmful prescription drugs, maternal characteristics associated with the prescribing of potentially harmful drugs during pregnancy were described according to the Swedish and Australian systems. These characteristics included sociodemographics, chronic diseases and healthcare system utilisation, and are listed in ESM Table 5. Crude odds ratios (OR) with their 95\% confidence intervals were calculated using univariate logistic regression models, accounting for correlations within women with multiple pregnancies by using generalised estimating equations with a binomial distribution. The study population for this analysis was restricted to women enrolled in the French national health insurance general scheme for salaried workers, representing $82.7 \%$ of all pregnancies included in this study, for whom complete data are available to define maternal characteristics. The association between each maternal characteristic and potentially harmful drug prescribing was therefore described in this population and in women with no chronic diseases.

In addition, prevalence estimates were reported for the prescription of the most harmful drugs or drug classes during pregnancy according to the French Reference Centre for Teratogenic Agents (CRAT) [26]. All ATC codes are provided in ESM Table 6.

\section{Results}

A total of 1,844,447 pregnancies starting in 2016 or 2017 were included in the study population, of which $1,348,098$ (73.1\%) ended in a live birth, 374,483 (20.3\%) ended in an induced abortion (elective or therapeutic), 69,127 (3.7\%) ended in a spontaneous abortion, 23,134 (1.3\%) ended in an ectopic pregnancy, $7049(0.4 \%)$ ended in a stillbirth and $22,556(1.2 \%)$ ended as a result of other outcomes (Fig. 1).

Among the study population, 1,682,156 pregnancies $(91.2 \%)$ were exposed to at least one reimbursed drug, with a median of six different drugs (interquartile range [IQR] 4-9). After exclusion of reimbursements for misoprostol and hormones, a total of 1097 different drugs were prescribed in this population (Fig. 1).

\subsection{Prevalence of Potentially Harmful Drug Prescribing During Pregnancy According to Two Classification Systems}

\subsubsection{Differences Between the Australian and Swedish Risk Classification Systems}

Of the 1097 different drugs, $699(63.7 \%)$ were listed in the Swedish system and 692 (63.1\%) were listed in the Australian system (Fig. 1).

Considering all pregnancy outcomes, the prevalence of potentially harmful drug prescribing during pregnancy was higher according to the Australian risk classification system (3.9\%; 72,568 pregnancies) than according to the Swedish system $(2.2 \% ; 40,131$ pregnancies), and increased to $9.2 \%$ and $6.9 \%$, respectively, when taking into account drugs that are contraindicated during pregnancy in France. These prevalence rates were lower when the study population was restricted to live births (1.8\% vs. $2.2 \%$, and $3.8 \%$ vs. $3.9 \%$ for the Swedish and Australian systems, respectively), and higher when the study population was restricted to induced 


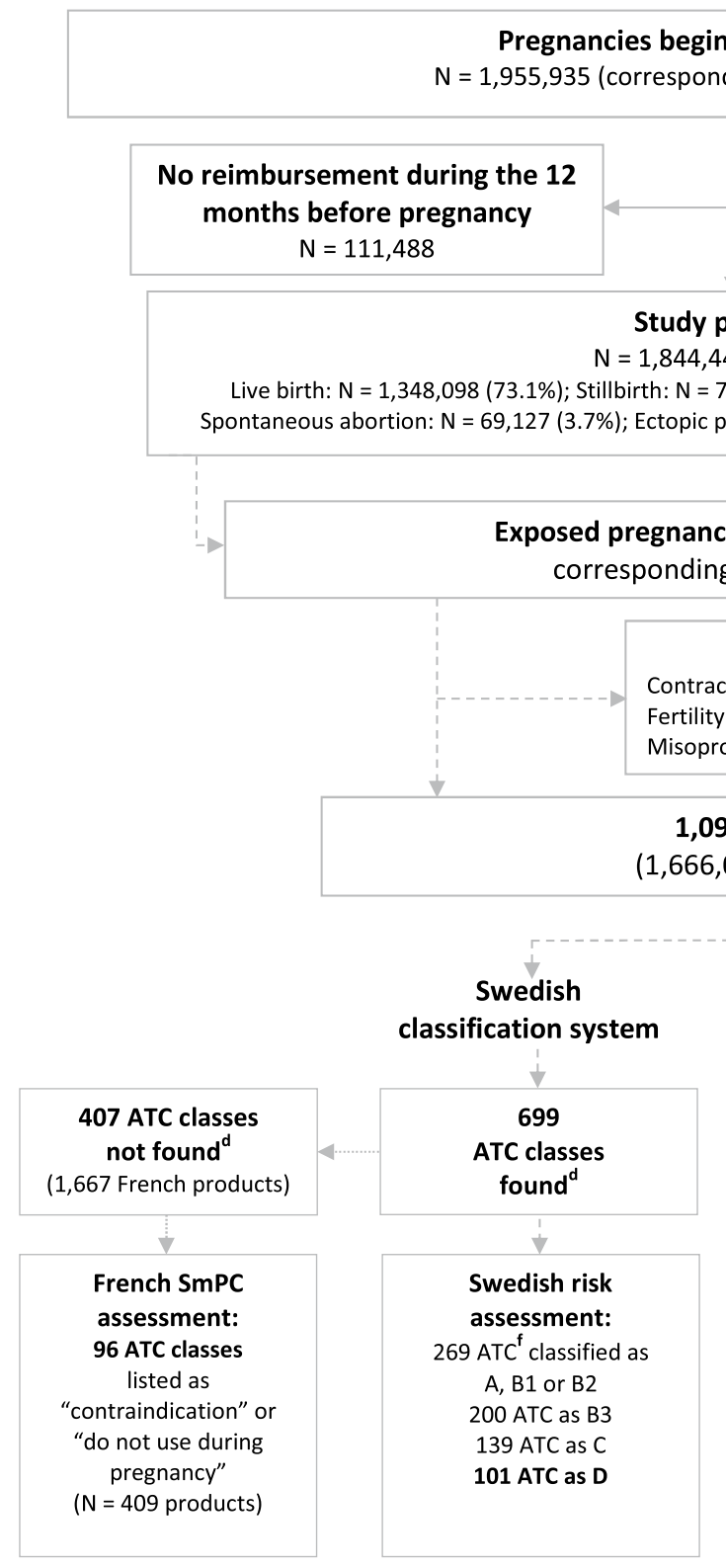

Fig. 1 Flowchart: definition of the study population and classification of ATC codes according to the two classification systems. Solid lines correspond to the definition of the study population, while dotted lines refer to the attribution of risk categories to ATC classes prescribed to pregnant women exposed to at least one drug during pregnancy. ${ }^{a}$ Hydatidiform mole or other abnormal products of conception. ${ }^{\mathrm{b}}$ Excluding homeopathic medicines. ${ }^{\mathrm{c}}$ Fifth-level ATC classes. ${ }^{\mathrm{d}}$ Nine ATC classes corresponding to drug combinations (A02AD01, A06AD10, B01AC30, B05BA10, B05XA31, C03EA01, N01BB52, S01CA01 and S01XA20) are classified in both groups: the Swedish risk category was only applied to French products composed of the

abortions. A decrease in prevalence rates was observed throughout pregnancy according to both the Australian and Swedish systems (Table 2).
29 excluded ATC classes

(164,823 pregnancies)

treatment: $\mathrm{N}=18$ ATC classes (133,855 pregnancies)

1,097 ATC classes

66,064 pregnancies)
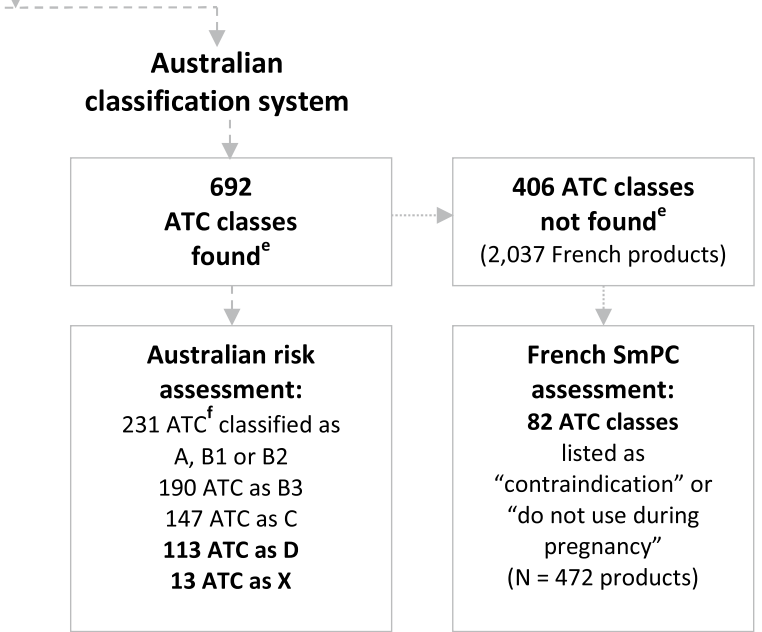

same molecules. ${ }^{\mathrm{e}} \mathrm{ATC}$ class B02BD02 is classified in both groups, as all types of coagulation factor VIII are listed in the Australian classification system except for turoctocog alfa and human coagulation

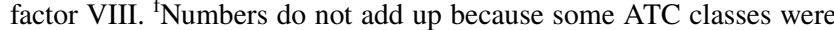
assigned different risk categories due, in particular, to the existence of different routes of administration for the same ATC class, corresponding to different risk categories (e.g., tobramycin for inhalation classified as B3, and tobramycin for injection classified as D; see ESM Table 4 for other reasons). ATC anatomical therapeutic chemical, SmPC summary of product characteristics

Among pregnant women to whom at least one potentially harmful drug was prescribed, $2.9 \%$ and $5.3 \%$ of women had two or more different potentially harmful drugs according 
to the Swedish and Australian systems, respectively (9.2\% and $11.2 \%$ when also considering drugs contraindicated in France). Furthermore, $20.0 \%$ and $30.2 \%$ of women were reimbursed for a potentially harmful drug two or more times during pregnancy according to the Swedish and Australian systems, respectively ( $17.2 \%$ and $24.2 \%$ ). In addition to the potentially harmful drug, a median of 2.0 (IQR 1-3) drugs were also dispensed on the same day, according to both systems.

Potentially harmful drugs were mainly prescribed by hospital and general practitioners regardless of the classification system used $(40.8 \%$ and $34.3 \%$ according to the Swedish system, and $39.3 \%$ and $36.5 \%$ according to the Australian system). Gynaecologists accounted for $10.3 \%$ and $7.6 \%$ of all potentially harmful drug prescriptions, respectively.

\subsubsection{Sensitivity Analyses}

When considering category C (or categories B3 and C) [see ESM Table 3], the prevalence of potentially harmful drug prescribing increased to $23.5 \%$ (46.0\%) according to the Australian system and $44.3 \%$ (71.7\%) according to the Swedish system (Table 2).
When the reimbursement window was extended to the 90-day period before pregnancy, the prevalence increased to $6.7 \%$ (18.7\% when considering drugs contraindicated in France) according to the Australian system and 4.1\% (16.2\%) according to the Swedish system (Table 2).

\subsection{Nature of Potentially Harmful Drugs Prescribed during Pregnancy}

\subsubsection{Differences Between the Australian and Swedish Classification Systems}

Table 3 reports the potentially harmful drug prescribing prevalence rates in descending order, according to the Swedish or Australian systems, for drugs with an exposure rate of at least 1 per 10,000 pregnancies, i.e. 40 different potentially harmful drugs. Twenty $(50 \%)$ of these drugs were not common to both classifications. Among these 20 drugs, 13 were classified as potentially harmful in the Australian system but not in the Swedish system: four of these drugs were not found in the Swedish system (chlorpromazine, tretinoin for topical use, albendazole, retinol for systemic use [FSU]), while nine drugs were

Table 2 Prevalence of potentially harmful drug prescribing during pregnancy according to the Swedish and Australian risk classification systems and data from French SmPCs

\begin{tabular}{|c|c|c|c|c|}
\hline & \multicolumn{2}{|c|}{ Swedish classification $[N(\%)]$} & \multicolumn{2}{|c|}{ Australian classification $[N(\%)]$} \\
\hline & Category D & $\begin{array}{l}\text { Category D or French } \\
\text { contraindication }\end{array}$ & Category D or X & $\begin{array}{l}\text { Category } \mathrm{D}, \mathrm{X} \text { or } \\
\text { French contraindica- } \\
\text { tion }\end{array}$ \\
\hline All pregnancies & $40,131(2.2)$ & $127,438(6.9)$ & $72,568(3.9)$ & $169,020(9.2)$ \\
\hline \multicolumn{5}{|l|}{ By pregnancy outcome } \\
\hline Live births & $24,169(1.8)$ & $73,363(5.4)$ & $51,500(3.8)$ & $114,071(8.5)$ \\
\hline Stillbirths & $164(2.3)$ & $497(7.1)$ & $301(4.3)$ & $715(10.1)$ \\
\hline Induced abortions & $13,590(3.6)$ & $44,953(12.0)$ & $17,223(4.6)$ & $44,808(12.0)$ \\
\hline Spontaneous abortions & $1295(1.9)$ & $5317(7.7)$ & $2154(3.1)$ & $5817(8.4)$ \\
\hline Ectopic pregnancies & $454(2.0)$ & $1553(6.7)$ & $689(3.0)$ & $1677(7.2)$ \\
\hline Other $^{\mathrm{a}}$ & $459(2.0)$ & $1755(7.8)$ & $701(3.1)$ & $1932(8.6)$ \\
\hline \multicolumn{5}{|l|}{ By trimester } \\
\hline First trimester & $16,055(1.2)$ & $50,379(3.7)$ & $32,585(2.4)$ & $75,259(5.6)$ \\
\hline Second trimester & $7959(0.6)$ & $18,203(1.4)$ & $22,343(1.7)$ & 39,207 (2.9) \\
\hline Third trimester & $6,105(0.5)$ & $14,116(1.1)$ & $17,619(1.3)$ & $27,473(2.0)$ \\
\hline \multicolumn{5}{|l|}{ Sensitivity analysis } \\
\hline \multicolumn{5}{|l|}{ Exposure definition } \\
\hline Including $T-1^{\mathrm{b}}$ & $74,937(4.1)$ & $298,541(16.2)$ & $123,414(6.7)$ & $345,578(18.7)$ \\
\hline \multicolumn{5}{|l|}{ Outcome definition } \\
\hline Including category $C$ drugs & $816,300(44.3)$ & $851,448(46.2)$ & $432,732(23.5)$ & $490,445(26.6)$ \\
\hline Including category $C$ and $B 3$ drugs & $1,323,143(71.7)$ & $1,344,673(72.9)$ & $847,869(46.0)$ & $882,985(47.9)$ \\
\hline
\end{tabular}

SmPCs Summary of Product Characteristics Figures in italics refer to the results of the sensitivity analyses

${ }^{a}$ Hydatidiform mole or other abnormal products of conception

${ }^{\mathrm{b}}$ With the dispensing window including the trimester before pregnancy (90-day period before the beginning of pregnancy) 
classified in another risk category (C: nicotine, paroxetine; B3: fluconazole FSU, lamotrigine, hydroxychloroquine, adapalene, simvastatin; A/B3: interferon $\beta-1 \mathrm{a} ; \mathrm{B} 2$ : etanercept). Finally, the remaining seven drugs were classified as potentially harmful in the Swedish system but not in the Australian system: four of these drugs were not found in the Australian system (sulfamethoxazole/trimethoprim, lymecycline, diclofenac/misoprostol, irbesartan/diuretics), and three drugs were classified in another risk category (B3: clonazepam; B1: ondansetron; A: erythromycin FSU) (Table 3).

Overall, when restricting the drugs reimbursed to pregnant women to the 549 ATCs common to the Swedish and Australian classification systems, a kappa coefficient of $0.81(0.74-0.87)$ indicated good agreement between the two classification systems. The 30 potentially harmful drugs that differed between the two systems are reported in ESM Table 7.

The five potentially harmful drugs most commonly prescribed according to the Swedish system were doxycycline FSU, erythromycin FSU, ondansetron, sulfamethoxazole/ trimethoprim and azathioprine, and, according to the Australian system, doxycycline, nicotine, fluconazole FSU, paroxetine and lamotrigine (Table 3 and ESM Table 8). Of the drugs contraindicated during pregnancy in France, in addition to NSAIDs (classified as $\mathrm{C}$ in the Swedish and Australian systems), the most commonly prescribed were tramadol/paracetamol combination, thiocolchicoside, ofloxacin FSU, progesterone/estrogen vaginal tablet and dexamethasone/oxytetracycline for ophthalmological use (ESM Table 8).

\subsubsection{Potentially Harmful Drug Prescribing According to Pregnancy Outcomes and Trimesters}

Induced abortion represented more than one-half of all pregnancy outcomes for cyproterone, primidone, thalidomide, teriflunomide, retinoids FSU, NSAIDs FSU and tetracyclines (Tables 3, 4). Ectopic pregnancy was the most commonly observed outcome (42.7\%) following methotrexate prescribing in both indications (antineoplastic and immunosuppressant agent).

The highest prevalence of teratogenic drug prescribing was observed during the first trimester of pregnancy, i.e., the highest risk period. Prescribing of foetotoxic drugs decreased during the second and third trimesters (highest risk period), but remained high, especially for NSAIDs, from the sixth month of pregnancy onwards (Table 4 and ESM Table 9). Similar trends were observed for valproic acid/ valpromide, which are both teratogenic and foetotoxic, for which the most commonly observed outcome was induced abortion (41.8\%) (Table 4).

\subsection{Maternal Characteristics Associated with Potentially Harmful Drug Prescribing During Pregnancy}

Maternal characteristics associated with potentially harmful drug prescribing during pregnancy are shown in Table 5 . Considering both systems, eligibility for a disability allowance, chronic diseases, polymedication (five or more drugs), alcoholism and illicit drug use were the strongest maternal characteristics $(\mathrm{OR} \geq 2)$ associated with an increased risk of potentially harmful drug prescribing during pregnancy. In women with no chronic diseases, the only maternal characteristic remaining strongly associated in both systems was polymedication (five or more drugs).

\section{Discussion}

Based on data for nearly 2 million pregnancies beginning in 2016-2017, this study provides the first nationwide estimation of the prevalence of potentially harmful drug prescribing during pregnancy in France according to the Swedish and Australian risk classification systems (2.2\% and 3.9\%, respectively), with good agreement between the two systems. This prevalence increased to $9.2 \%$ when drugs contraindicated during pregnancy in France were taken into account. Most women with a prescription of potentially harmful drugs had only one prescription. The highest prevalence of teratogenic drug prescribing was observed during the first trimester and, among foetotoxic drug classes prescribed after the first trimester, the prevalence of NSAID prescribing was high.

\subsection{Comparison with Previous Studies}

Most studies evaluating the nationwide prevalence of potentially harmful drug use were based on the FDA risk classification system [2]. Although direct comparisons between studies are difficult due to differences in methodology and differences in marketed drugs across countries, the prevalence rates reported in these studies using only categories $\mathrm{D}$ and $\mathrm{X}$ were comparable with those observed in this study, ranging from 1.1 to $5.8 \%$ for pregnancies ending in a live birth [20,27-31]. NSAIDs are category $\mathrm{C}$ drugs according to the Swedish and Australian systems and were therefore not considered to be potentially harmful in our main analysis. However, this study showed a high prevalence of NSAID prescribing after the first trimester, albeit lower than the rates observed in the 1990s in two different French regions $[11,13]$. This observed prevalence rate was higher than in Norway [32], The Netherlands [33] or Sweden [34]. Variations in the proportion of over-the-counter (OTC) NSAID 
Table 3 Prevalence of potentially harmful drug prescribing at any time during pregnancy, according to the Swedish or Australian systems (for drugs with at least 1 per 10,000 pregnancies exposed)

\begin{tabular}{|c|c|c|c|c|c|c|c|c|c|}
\hline \multirow[t]{2}{*}{ ATC code } & \multirow[t]{2}{*}{ ATC name } & \multirow{2}{*}{$\begin{array}{l}\text { Source } \\
\text { (clas- } \\
\text { sification } \\
\text { system) }\end{array}$} & \multirow{2}{*}{$\begin{array}{l}N \text { (preva- } \\
\text { lence per } \\
100 \text { preg- } \\
\text { nancies) }\end{array}$} & \multicolumn{6}{|c|}{ By pregnancy outcome [row \% (prevalence per 100 pregnancies)] } \\
\hline & & & & $\begin{array}{l}\text { Live births } \\
{[N=1,348,098]}\end{array}$ & $\begin{array}{l}\text { Induced } \\
\text { abortions } \\
{[N=374,483]}\end{array}$ & $\begin{array}{l}\text { Spontaneous } \\
\text { abortions } \\
{[N=69,127]}\end{array}$ & $\begin{array}{l}\text { Ectopic } \\
\text { pregnancies } \\
{[N=23,134]}\end{array}$ & $\begin{array}{l}\text { Stillbirths } \\
{[N=7049]}\end{array}$ & $\begin{array}{l}\text { Other }^{\mathrm{a}} \\
{[N=22,556]}\end{array}$ \\
\hline N07BA01 & Nicotine & $\begin{array}{l}\text { Austral- } \\
\text { ian }\end{array}$ & $\begin{array}{l}17,567 \\
(0.952)\end{array}$ & $95.6(1.246)$ & $2.1(0.098)$ & $1.3(0.333)$ & $0.2(0.125)$ & $0.5(1.135)$ & $0.4(0.275)$ \\
\hline J01AA02 & $\begin{array}{l}\text { Doxycy- } \\
\text { cline }\end{array}$ & $\begin{array}{l}\text { Swedish/ } \\
\text { Austral- } \\
\text { ian }\end{array}$ & $\begin{array}{l}14,726 \\
(0.798)\end{array}$ & $28.8(0.315)$ & $65.3(2.568)$ & $3.6(0.765)$ & $0.7(0.471)$ & $0.1(0.312)$ & $1.4(0.913)$ \\
\hline J02AC01 & Fluconazole & $\begin{array}{l}\text { Austral- } \\
\text { ian }\end{array}$ & $9836(0.533)$ & $83.4(0.608)$ & $12.8(0.337)$ & $2.2(0.314)$ & $0.7(0.290)$ & $0.3(0.369)$ & $0.6(0.279)$ \\
\hline N06AB05 & Paroxetine & $\begin{array}{l}\text { Austral- } \\
\text { ian }\end{array}$ & $7376(0.400)$ & $67.4(0.369)$ & $26.0(0.512)$ & $3.7(0.392)$ & $1.0(0.333)$ & $0.5(0.482)$ & $1.4(0.452)$ \\
\hline J01FA01 & $\begin{array}{l}\text { Erythromy- } \\
\text { cin }\end{array}$ & Swedish & $4989(0.270)$ & $94.3(0.349)$ & $3.6(0.048)$ & $1.2(0.087)$ & $0.1(0.030)$ & $0.4(0.255)$ & $0.4(0.089)$ \\
\hline A04AA01 & $\begin{array}{l}\text { Ondanse- } \\
\text { tron }\end{array}$ & Swedish & $4533(0.246)$ & $92.7(0.312)$ & $5.0(0.060)$ & $1.1(0.071)$ & $0.0(0.009)$ & $0.7(0.454)$ & $0.4(0.089)$ \\
\hline N03AX09 & Lamotrigine & $\begin{array}{l}\text { Austral- } \\
\text { ian }\end{array}$ & $4461(0.242)$ & $77.4(0.256)$ & $15.7(0.187)$ & $4.2(0.271)$ & $0.9(0.182)$ & $0.5(0.326)$ & $1.2(0.239)$ \\
\hline J01EE01 & $\begin{array}{l}\text { Sulfameth- } \\
\text { oxazole/ } \\
\text { trimetho- } \\
\text { prim }\end{array}$ & Swedish & $3897(0.211)$ & $85.4(0.247)$ & $10.1(0.105)$ & $2.2(0.126)$ & $0.4(0.073)$ & $0.4(0.227)$ & $1.4(0.248)$ \\
\hline N05AA01 & $\begin{array}{l}\text { Chlorprom- } \\
\text { azine }\end{array}$ & $\begin{array}{l}\text { Austral- } \\
\text { ian }\end{array}$ & $3453(0.187)$ & $91.3(0.234)$ & $5.3(0.049)$ & $2.2(0.110)$ & $0.1(0.017)$ & $0.6(0.270)$ & $0.5(0.080)$ \\
\hline P01BA02 & $\begin{array}{l}\text { Hydroxy- } \\
\text { chloro- } \\
\text { quine }\end{array}$ & $\begin{array}{l}\text { Austral- } \\
\text { ian }\end{array}$ & $2625(0.142)$ & $80.5(0.157)$ & $10.7(0.075)$ & $5.1(0.195)$ & $1.0(0.112)$ & $0.9(0.340)$ & $1.7(0.200)$ \\
\hline D10AD03 & Adapalene & $\begin{array}{l}\text { Austral- } \\
\text { ian }\end{array}$ & $1920(0.104)$ & $68.8(0.098)$ & $27.1(0.139)$ & $2.1(0.059)$ & $0.9(0.073)$ & $0.3(0.085)$ & $0.8(0.067)$ \\
\hline L04AX01 & $\begin{array}{l}\text { Azathio- } \\
\text { prine }\end{array}$ & $\begin{array}{l}\text { Swedish/ } \\
\text { Austral- } \\
\text { ian }\end{array}$ & $1654(0.090)$ & $83.1(0.102)$ & $8.8(0.039)$ & $4.5(0.108)$ & $1.1(0.078)$ & $1.0(0.241)$ & $1.5(0.106)$ \\
\hline J01AA04 & $\begin{array}{l}\text { Lymecy- } \\
\text { cline }\end{array}$ & Swedish & $1508(0.082)$ & $56.6(0.063)$ & $36.7(0.148)$ & $4.2(0.091)$ & $1.3(0.082)$ & $0.3(0.071)$ & $0.9(0.062)$ \\
\hline D10AD01 & Tretinoin & $\begin{array}{l}\text { Austral- } \\
\text { ian }\end{array}$ & 1095 (0.059) & $69.9(0.057)$ & $25.8(0.076)$ & $2.1(0.033)$ & $1.3(0.061)$ & $0.4(0.057)$ & $0.5(0.027)$ \\
\hline P02CA03 & $\begin{array}{l}\text { Albenda- } \\
\text { zole }\end{array}$ & $\begin{array}{l}\text { Austral- } \\
\text { ian }\end{array}$ & $1063(0.058)$ & $78.5(0.062)$ & $17.0(0.048)$ & $2.3(0.035)$ & $1.3(0.061)$ & $0.3(0.043)$ & $0.7(0.031)$ \\
\hline M04AC01 & Colchicine & $\begin{array}{l}\text { Swedish/ } \\
\text { Austral- } \\
\text { ian }\end{array}$ & $791(0.043)$ & $82.3(0.048)$ & $12.6(0.027)$ & $3.0(0.035)$ & $0.6(0.022)$ & $0.5(0.057)$ & $0.9(0.031)$ \\
\hline C10AA05 & Atorvastatin & $\begin{array}{l}\text { Swedish/ } \\
\text { Austral- } \\
\text { ian }\end{array}$ & $593(0.032)$ & $66.8(0.029)$ & $23.4(0.037)$ & $4.9(0.042)$ & $2.2(0.056)$ & $0.8(0.071)$ & $1.9(0.049)$ \\
\hline C09AA05 & Ramipril & $\begin{array}{l}\text { Swedish/ } \\
\text { Austral- } \\
\text { ian }\end{array}$ & $574(0.031)$ & $60.3(0.026)$ & $30.3(0.046)$ & $5.4(0.045)$ & $1.2(0.030)$ & $1.0(0.085)$ & $1.7(0.044)$ \\
\hline N03AG01 & $\begin{array}{l}\text { Valproic } \\
\text { acid }\end{array}$ & $\begin{array}{l}\text { Swedish/ } \\
\text { Austral- } \\
\text { ian }\end{array}$ & $569(0.031)$ & $52.7(0.022)$ & $40.1(0.061)$ & $4.0(0.033)$ & $1.2(0.030)$ & $0.7(0.057)$ & $1.2(0.031)$ \\
\hline N03AF01 & $\begin{array}{l}\text { Carbamaz- } \\
\text { epine }\end{array}$ & $\begin{array}{l}\text { Swedish/ } \\
\text { Austral- } \\
\text { ian }\end{array}$ & $567(0.031)$ & $58.9(0.025)$ & $31.0(0.047)$ & $4.8(0.039)$ & $3.2(0.078)$ & $0.9(0.071)$ & $1.2(0.031)$ \\
\hline A11CA01 & $\begin{array}{l}\text { Retinol (vit } \\
\text { a) }\end{array}$ & $\begin{array}{l}\text { Austral- } \\
\text { ian }\end{array}$ & $534(0.029)$ & $93.6(0.037)$ & $4.1(0.006)$ & $1.1(0.009)$ & $0.2(0.004)$ & $0.6(0.043)$ & $0.4(0.009)$ \\
\hline
\end{tabular}


Table 3 (continued)

\begin{tabular}{|c|c|c|c|c|c|c|c|c|c|}
\hline \multirow[t]{2}{*}{ ATC code } & \multirow[t]{2}{*}{ ATC name } & \multirow{2}{*}{$\begin{array}{l}\text { Source } \\
\text { (clas- } \\
\text { sification } \\
\text { system) }\end{array}$} & \multirow{2}{*}{$\begin{array}{l}N \text { (preva- } \\
\text { lence per } \\
100 \text { preg- } \\
\text { nancies) }\end{array}$} & \multicolumn{6}{|c|}{ By pregnancy outcome [row \% (prevalence per 100 pregnancies)] } \\
\hline & & & & $\begin{array}{l}\text { Live births } \\
{[N=1,348,098]}\end{array}$ & $\begin{array}{l}\text { Induced } \\
\text { abortions } \\
{[N=374,483]}\end{array}$ & $\begin{array}{l}\text { Spontaneous } \\
\text { abortions } \\
{[N=69,127]}\end{array}$ & $\begin{array}{l}\text { Ectopic } \\
\text { pregnancies } \\
{[N=23,134]}\end{array}$ & $\begin{array}{l}\text { Stillbirths } \\
{[N=7049]}\end{array}$ & $\begin{array}{l}\text { Other }^{\mathrm{a}} \\
{[N=22,556]}\end{array}$ \\
\hline N03AX11 & Topiramate & $\begin{array}{l}\text { Swedish/ } \\
\text { Austral- } \\
\text { ian }\end{array}$ & $496(0.027)$ & $56.3(0.021)$ & $36.5(0.048)$ & $5.2(0.038)$ & $1.0(0.022)$ & $0.4(0.028)$ & $0.6(0.013)$ \\
\hline J01GB01 & Tobramycin & $\begin{array}{l}\text { Swedish/ } \\
\text { Austral- } \\
\text { ian }\end{array}$ & $451(0.024)$ & $92.5(0.031)$ & $4.9(0.006)$ & $1.6(0.010)$ & $0.2(0.004)$ & $0.2(0.014)$ & $0.7(0.013)$ \\
\hline C09AA04 & Perindopril & $\begin{array}{l}\text { Swedish/ } \\
\text { Austral- } \\
\text { ian }\end{array}$ & $436(0.024)$ & $61.9(0.020)$ & $29.4(0.034)$ & $5.3(0.033)$ & $1.6(0.030)$ & $0.7(0.043)$ & $1.1(0.022)$ \\
\hline N05AN01 & Lithium & $\begin{array}{l}\text { Swedish/ } \\
\text { Austral- } \\
\text { ian }\end{array}$ & $362(0.020)$ & $57.2(0.015)$ & $35.4(0.034)$ & $3.6(0.019)$ & $2.2(0.035)$ & $0.0(0.000)$ & $1.7(0.027)$ \\
\hline M01AB55 & $\begin{array}{l}\text { Diclofenac/ } \\
\text { misopros- } \\
\text { tol }^{\text {b }}\end{array}$ & Swedish & 357 (0.019) & $60.2(0.016)$ & $30.0(0.029)$ & $6.7(0.035)$ & $1.1(0.017)$ & $0.3(0.014)$ & $1.7(0.027)$ \\
\hline C09CA04 & Irbesartan & $\begin{array}{l}\text { Swedish/ } \\
\text { Austral- } \\
\text { ian }\end{array}$ & $322(0.017)$ & $58.7(0.014)$ & $32.9(0.028)$ & $5.6(0.026)$ & $0.9(0.013)$ & $0.6(0.028)$ & $1.2(0.018)$ \\
\hline L03AB07 & $\begin{array}{c}\text { Interferon } \\
\beta-1 \mathrm{a}\end{array}$ & $\begin{array}{l}\text { Austral- } \\
\text { ian }\end{array}$ & $310(0.017)$ & 79.7 (0.018) & $13.5(0.011)$ & $2.6(0.012)$ & $1.9(0.026)$ & $1.0(0.043)$ & $1.3(0.018)$ \\
\hline N03AE01 & $\begin{array}{c}\text { Clonaz- } \\
\text { epam }\end{array}$ & Swedish & $288(0.016)$ & $77.1(0.016)$ & $16.7(0.013)$ & $4.9(0.020)$ & $0.0(0.000)$ & $0.3(0.014)$ & $1.0(0.013)$ \\
\hline B01AA03 & Warfarin & $\begin{array}{l}\text { Swedish/ } \\
\text { Austral- } \\
\text { ian }\end{array}$ & $251(0.014)$ & $54.2(0.010)$ & $30.7(0.021)$ & $9.6(0.035)$ & $2.4(0.026)$ & $0.8(0.028)$ & $2.4(0.027)$ \\
\hline G03HA01 & $\begin{array}{l}\text { Cyproter- } \\
\text { one }\end{array}$ & $\begin{array}{l}\text { Swedish/ } \\
\text { Austral- } \\
\text { ian }\end{array}$ & $251(0.014)$ & $36.3(0.007)$ & $58.2(0.039)$ & $3.2(0.012)$ & $0.0(0.000)$ & $0.0(0.000)$ & $2.4(0.027)$ \\
\hline L04AB01 & Etanercept & $\begin{array}{c}\text { Austral- } \\
\text { ian }\end{array}$ & $235(0.013)$ & ) $74.5(0.013)$ & $19.1(0.012)$ & $3.8(0.013)$ & $1.3(0.013)$ & $0.4(0.014)$ & $0.9(0.009)$ \\
\hline C10AA01 & Simvastatin & $\begin{array}{c}\text { Austral- } \\
\text { ian }\end{array}$ & $232(0.013)$ & $68.1(0.012)$ & $22.0(0.014)$ & $6.9(0.023)$ & $0.4(0.004)$ & $1.3(0.043)$ & $1.3(0.013)$ \\
\hline C09CA03 & Valsartan & $\begin{array}{l}\text { Swedish/ } \\
\text { Austral- } \\
\text { ian }\end{array}$ & $222(0.012)$ & $57.7(0.009)$ & $32.4(0.019)$ & $6.3(0.020)$ & $1.8(0.017)$ & $0.5(0.014)$ & $1.4(0.013)$ \\
\hline C10AA07 & $\begin{array}{l}\text { Rosuvas- } \\
\text { tatin }\end{array}$ & $\begin{array}{l}\text { Swedish/ } \\
\text { Austral- } \\
\text { ian }\end{array}$ & $211(0.011)$ & $67.3(0.011)$ & $26.1(0.015)$ & $3.3(0.010)$ & $1.9(0.017)$ & $0.5(0.014)$ & $0.9(0.009)$ \\
\hline N03AF02 & $\begin{array}{l}\text { Oxcarbaz- } \\
\text { epine }\end{array}$ & $\begin{array}{l}\text { Swedish/ } \\
\text { Austral- } \\
\text { ian }\end{array}$ & $206(0.011)$ & $68.9(0.011)$ & $24.8(0.014)$ & $3.4(0.010)$ & $1.0(0.009)$ & $0.0(0.000)$ & $1.9(0.018)$ \\
\hline C09CA06 & $\begin{array}{l}\text { Candesar- } \\
\tan \end{array}$ & $\begin{array}{l}\text { Swedish/ } \\
\text { Austral- } \\
\text { ian }\end{array}$ & $196(0.011)$ & $59.7(0.009)$ & $28.1(0.015)$ & $6.6(0.019)$ & $1.5(0.013)$ & $1.5(0.043)$ & $2.6(0.022)$ \\
\hline C09DA04 & $\begin{array}{c}\text { Irbesartan/ } \\
\text { diuretics }\end{array}$ & Swedish & $190(0.010)$ & ) 65.3 (0.009) & $26.3(0.013)$ & $4.2(0.012)$ & $2.1(0.017)$ & $1.1(0.028)$ & $1.1(0.009)$ \\
\hline C09DB01 & $\begin{array}{l}\text { Valsartan/ } \\
\text { amlodi- } \\
\text { pine }\end{array}$ & $\begin{array}{l}\text { Swedish/ } \\
\text { Austral- } \\
\text { ian }\end{array}$ & $187(0.010)$ & $67.4(0.009)$ & $25.7(0.013)$ & $3.7(0.010)$ & $1.1(0.009)$ & $1.6(0.043)$ & $0.5(0.004)$ \\
\hline L04AX03 & $\begin{array}{l}\text { Methotrex- } \\
\text { ate }\end{array}$ & $\begin{array}{l}\text { Swedish/ } \\
\text { Austral- } \\
\text { ian }\end{array}$ & $187(0.010)$ & $31.0(0.004)$ & $31.6(0.016)$ & $3.7(0.010)$ & $30.5(0.246)$ & $1.6(0.043)$ & $1.6(0.013)$ \\
\hline
\end{tabular}

ATC Anatomical Therapeutic Chemical

${ }^{a}$ Hydatidiform mole or other abnormal products of conception

${ }^{\mathrm{b}}$ In France, ATC class M01AB55 only includes the combination of diclofenac and misoprostol (ARTOTEC ${ }^{\circledR}$, Pfizer, France) 


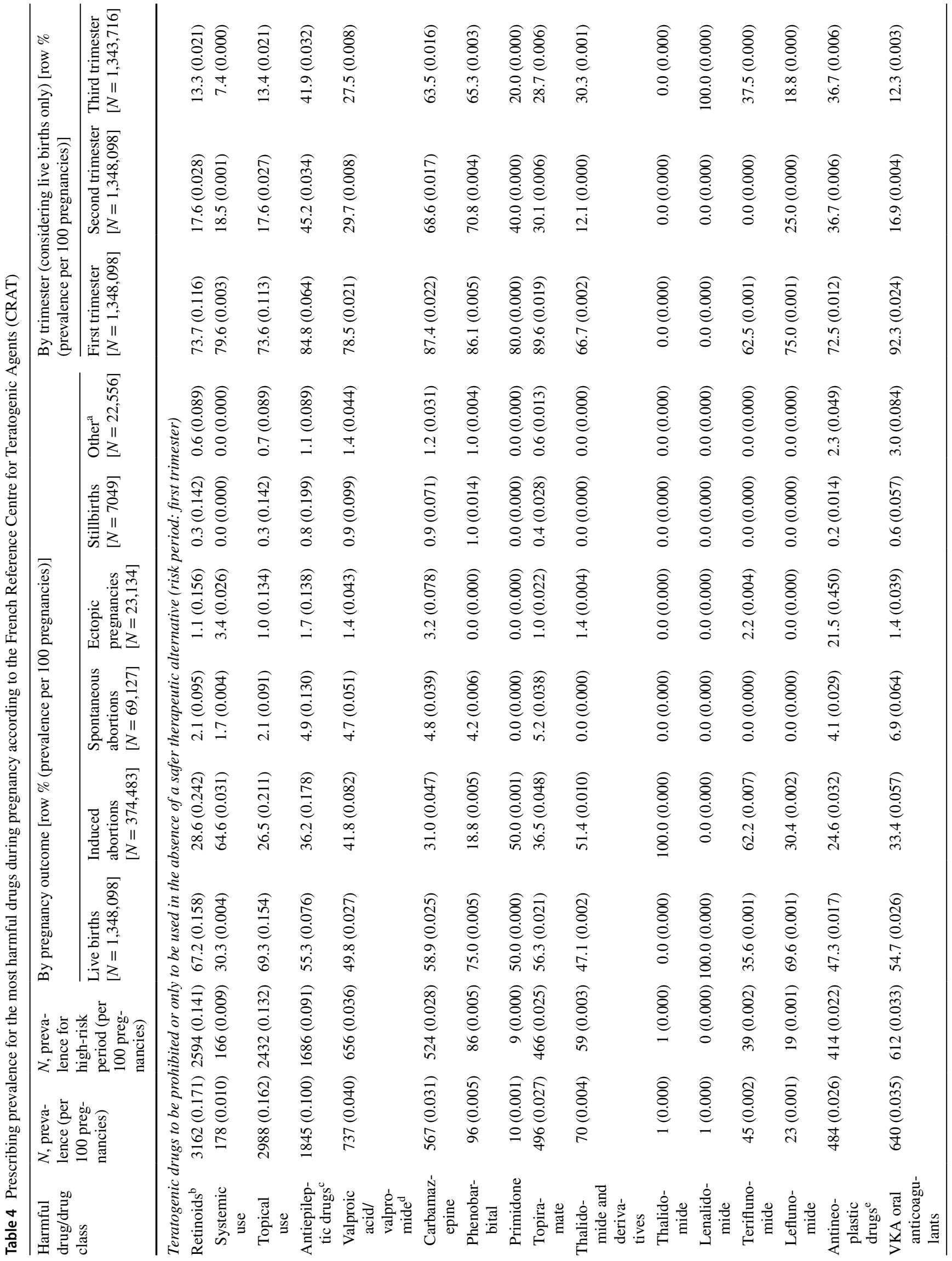




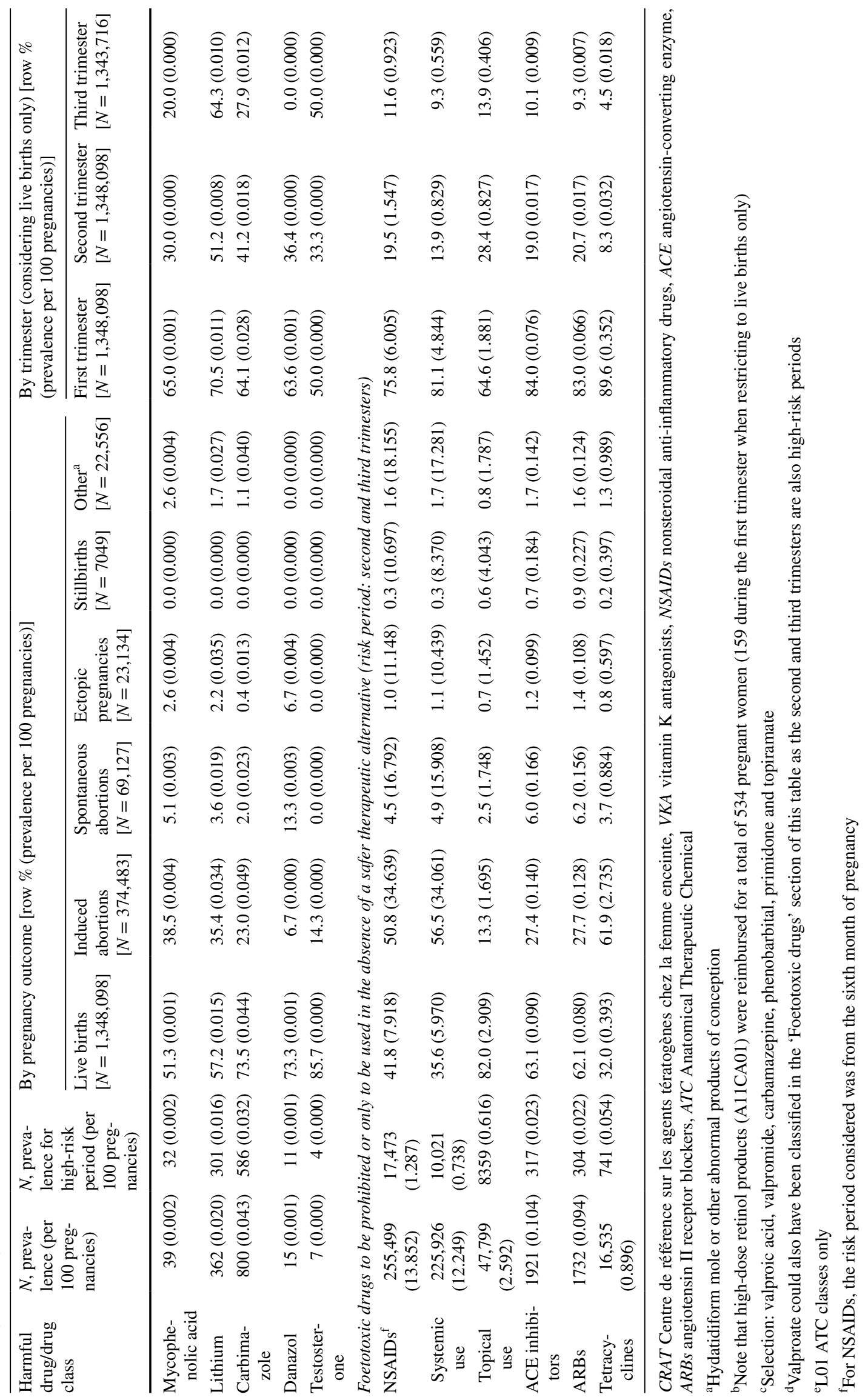




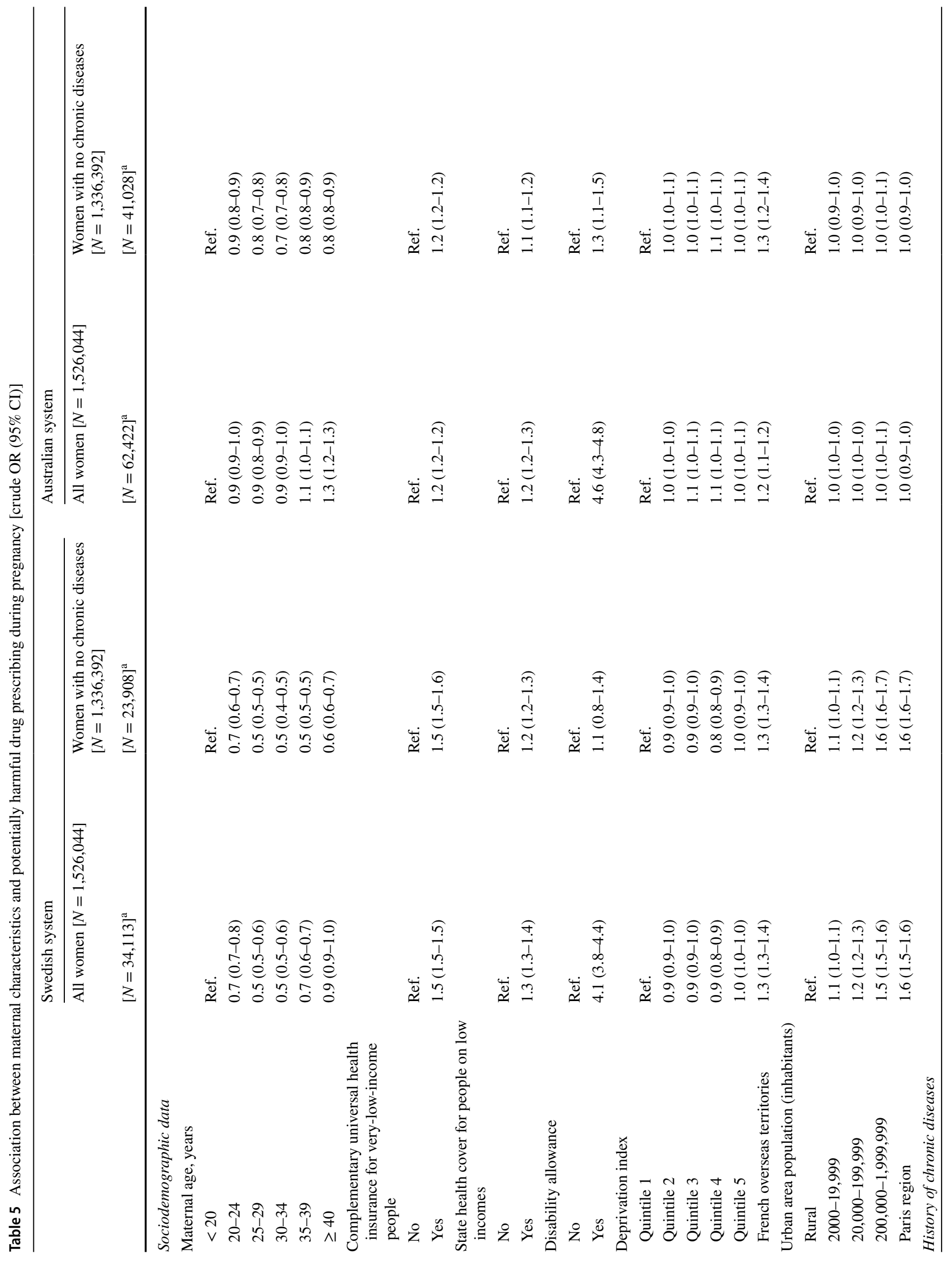


Dispensing of Potentially Harmful Drugs in pregnant women in France

1335

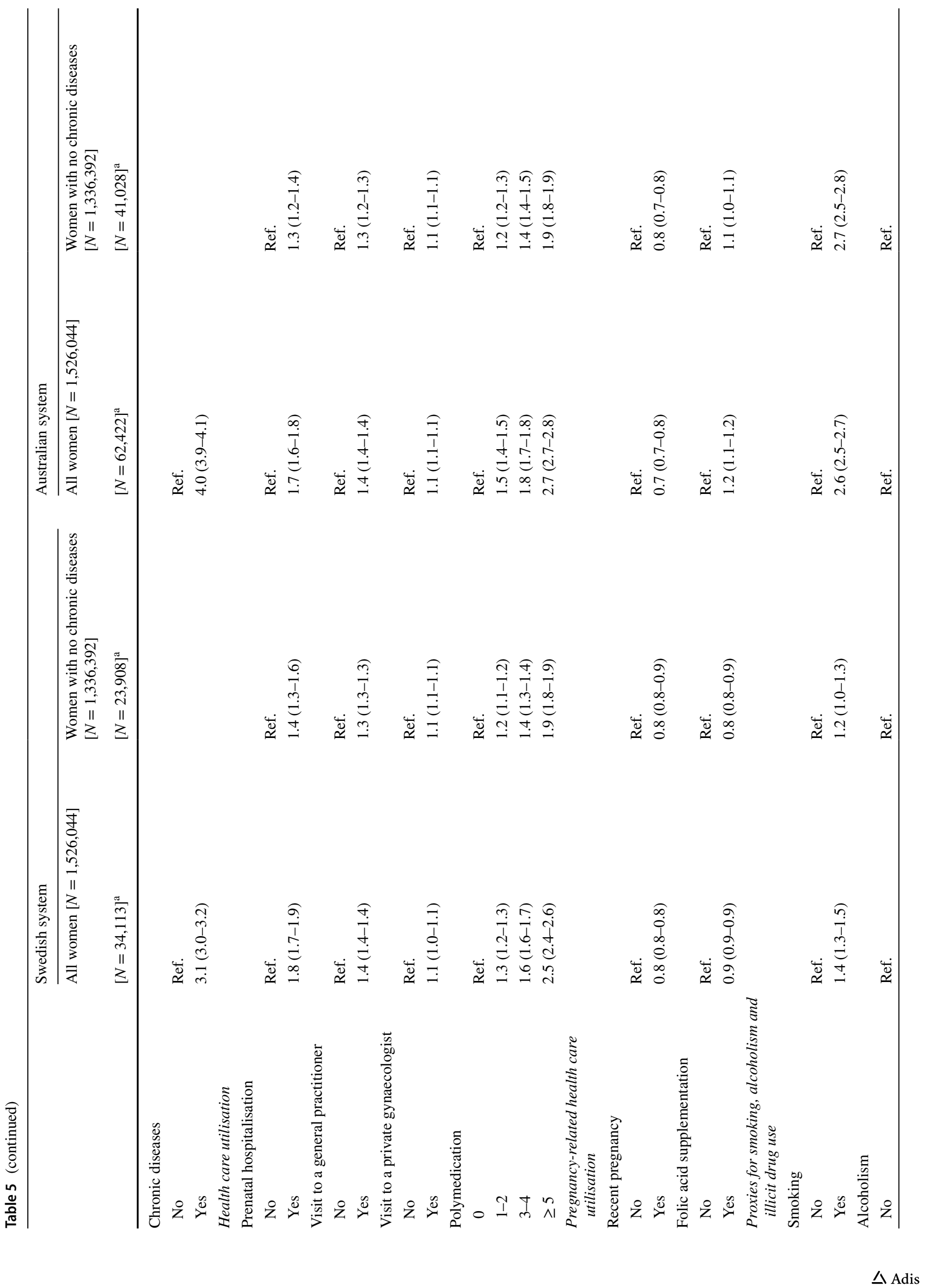


use across countries may also explain the observed differences, as these studies, including the present study, did not capture OTC drugs.

As described in previous European or North American studies, maternal characteristics such as chronic diseases, polymedication and young age were found to be associated with potentially harmful prescriptions during pregnancy [14, $28,35,36]$. However, other maternal characteristics associated with an increased risk of potentially harmful prescriptions were identified, including deprived women or those living in French overseas territories. These results may help inform the planning of subsequent causal studies to identify groups of pregnant women who could benefit the most from prepregnancy counselling.

\subsection{Clinical Implications of the Results}

Unlike most studies on harmful drug prescribing, our study population was not restricted to live births. Results regarding pregnancy outcomes must be interpreted with caution, as this descriptive study was not designed to allow any causal interpretations. On the one hand, we identified some previously reported patterns of use, such as off-label use of methotrexate in ectopic pregnancies [37], use of doxycycline for antibiotic prophylaxis in surgical abortions [38], and use of NSAIDs as analgesics in induced abortions [39, 40], which could therefore be interpreted as indication bias. On the other hand, the high abortion rates observed following exposure to valproic acid and derivatives, thalidomide and derivatives, or retinoids FSU were indicative and expected given the high teratogenicity of these drugs. In line with these considerations, the high proportion of pregnancies ending in abortion and exposed to cyproterone (50 and $100 \mathrm{mg}$ ), teriflunomide or antiepileptic drugs such as topiramate for which a therapeutic alternative exists, are a source of concern.

Overall, as expected and as previously reported [20, 41, 42], potentially harmful drug prescribing tended to decrease throughout pregnancy, in contrast with the trends observed for certain antiepileptic drugs, antineoplastic drugs, lithium, paroxetine or azathioprine, suggesting the difficulty of stopping vital treatments for certain chronic conditions, in which these drugs may present a higher benefit-risk balance. The declining although persistent prescription of vitamin $\mathrm{K}$ antagonists observed during the second and third trimesters may illustrate these clinical settings, as these drugs are the only treatment options available for women with artificial heart valves. However, this study was not designed to evaluate the appropriateness of drug prescribing in individual pregnant women.

Differences were observed between the prevalence rates estimated on the basis of the two classification systems used. This can be explained by differences in the nature of the 
drugs contained in the two classification systems, as some drugs are not marketed in either Australia (e.g., lymecycline) or Sweden (e.g., chlorpromazine), and as the drugs exempted from receiving a pregnancy risk category also differ. Certain marketed drug combinations are also not explicitly listed in the Australian system (e.g., sulfamethoxazole/trimethoprim) and were therefore not assigned any risk category in our study. However, the D/X risk category allocation differed for only 30 of the 549 drugs common to both systems (e.g., lamotrigine classified as B3 in Sweden versus D in Australia) and a good agreement was found between the two systems. Keeping in mind all the shortcomings inherent to classification systems [43, 44], this study therefore supports their utilisation as a convenient tool to assess potentially harmful drug prescribing at a population level based on claims data.

\subsection{Strengths and Limitations}

This is the first study to use risk classification systems to estimate the prevalence of potentially harmful drug prescribing during pregnancy based on French nationwide data, providing details on drug classes and ATC classes and maternal characteristics associated with the prescription of these drugs. All prescribed drugs reimbursed in the ambulatory setting, irrespective of their cost, and drugs for which hospitals receive additional funding (e.g., certain treatments administered for severe chronic diseases such as cancers, multiple sclerosis, inflammatory bowel disease, etc.) were considered. More than one-third of the drugs prescribed during pregnancy in this study were not classified in either the Swedish or Australian systems. Data from French SmPCs were therefore used in addition to the two classification systems, allowing more accurate estimation of prevalence rates.

Prescribing assessment was based on claims data, which do not indicate whether or not and when the woman actually took the medication. This may apply to drugs reimbursed during late pregnancy but actually used in the early postpartum period, such as NSAIDs prescribed for perineal pain [45]. However, exposure misclassification due to inaccurate estimations of pregnancy dates should be limited, as pregnancy dates were estimated using exact pregnancy outcome dates and gestational ages [19]. Another limitation was the impossibility to include certain pregnancies: spontaneous abortions not managed in hospital could not be identified, and anonymised induced abortions (up to $8 \%$ of all elective abortions in 2014), which can be requested by minors, could not be linked to drug reimbursement [19]. As the nationwide prevalence of potentially harmful drug prescribing also included foetotoxic drug prescribing during the first trimester, it may therefore have been overestimated as the use of foetotoxic drugs during this period should not be harmful for the foetus. Conversely, OTC drugs, as well as the majority of drugs administered in hospital, are not captured in the databases used, resulting in underestimation of prevalence rates. Finally, considering the descriptive design of this study and the absence of certain maternal characteristics (e.g., access to preconception counselling, contraception and appropriate pregnancy testing) due to the nature of the data used, the results of analyses of the association between maternal characteristics and potentially harmful drug prescribing should therefore be interpreted with this limitation in mind.

\section{Conclusion}

Based on nearly 2 million pregnancies beginning in 2016-2017 and identified from French nationwide data, this study showed that potentially harmful drug prescribing to pregnant women is not uncommon. For some of these drugs, especially NSAIDs, future research to determine the reasons for their prescription during pregnancy, is needed. The results of this study support comparative analysis of updated risk classification systems as a useful tool to assess potentially harmful drug prescribing during pregnancy in studies based on health care databases.

Supplementary Information The online version contains supplementary material available at https://doi.org/10.1007/s40264-021-01117-4.

Acknowledgements The authors thank Dr Saul, Medical Translator, for assistance in writing this manuscript.

\section{Declarations}

Funding No funding was received for this work.

Conflict of interest Pierre-Olivier Blotière, Christine Damase-Michel, Alain Weill and Géric Maura have no conflicts of interest to declare. Pierre-Olivier, Alain Weill, and Géric Maura are employees of the French National Health Insurance (CNAM). Christine Damase-Michel is Associate Professor in Pharmacology, and Hospital Practitioner, at Faculté de Médecine, Université de Toulouse UPS, Inserm CERPOP, CHU, Toulouse, France.

Availability of data and material No additional data are available from the author (French law to access the SNDS; https://www.snds.gouv.fr). Permanent access to the French healthcare databases is automatically granted to certain government agencies, public institutions and public service authorities; however, temporary access for studies and research is possible upon request to the national health data institute (INDS). All databases used in this study contained anonymous patient records.

Code availability Not applicable.

Author contributions All authors approved the final version of this article. Pierre-Olivier Blotière and Géric Maura designed the study and drafted the article, and Pierre-Olivier Blotière also conducted data collection and statistical analysis. All authors contributed substantially to the interpretation of the results. Christine Damase-Michel and Alain Weill provided critical revision of the manuscript for important intel- 
lectual content. All authors had full access to all of the study data (including statistical reports and tables) and take full responsibility for the integrity of the data and accuracy of the data analysis.

Ethics approval/consent to participate This observational study, which was based on the French healthcare databases, was approved by the French Data Protection Agency (Commission Nationale de l'Informatique et des Libertés, CNIL) and did not require patient consent or Ethics Committee approval. Patients and/or the public were not involved.

\section{Consent for publication Not applicable.}

Open Access This article is licensed under a Creative Commons Attribution-NonCommercial 4.0 International License, which permits any non-commercial use, sharing, adaptation, distribution and reproduction in any medium or format, as long as you give appropriate credit to the original author(s) and the source, provide a link to the Creative Commons licence, and indicate if changes were made. The images or other third party material in this article are included in the article's Creative Commons licence, unless indicated otherwise in a credit line to the material. If material is not included in the article's Creative Commons licence and your intended use is not permitted by statutory regulation or exceeds the permitted use, you will need to obtain permission directly from the copyright holder. To view a copy of this licence, visit http://creativecommons.org/licenses/by-nc/4.0/.

\section{References}

1. European Medicines Agency (EMA). Valproate and related substances: new measures to avoid valproate exposure in pregnancy endorsed. 2018. https://www.ema.europa.eu/en/medicines/human/ referrals/valproate-related-substances-0. Accessed 23 Apr 2019.

2. Daw JR, Hanley GE, Greyson DL, Morgan SG. Prescription drug use during pregnancy in developed countries: a systematic review. Pharmacoepidemiol Drug Saf. 2011;20:895-902.

3. Blattner CM, Danesh M, Safaee M, Murase JE. Understanding the new FDA pregnancy and lactation labeling rules. Int J Womens Dermatol. 2016;2:5-7.

4. Australian Government, Department of Health. Therapeutic Goods Administration (TGA). Prescribing medicines in pregnancy database. 2019. https://www.tga.gov.au/prescribing-medic ines-pregnancy-database. Accessed 3 Jan 2020.

5. Swedish Catalogue of Approved Drugs (FASS). https://www.fass. se/LIF/startpage. Accessed 3 Jan 2020.

6. Demailly R, Escolano S, Quantin C, Tubert-Bitter P, Ahmed I. Prescription drug use during pregnancy in France: a study from the national health insurance permanent sample. Pharmacoepidemiol Drug Saf. 2017;26:1126-34.

7. Araujo M, Hurault-Delarue C, Sommet A, Damase-Michel C, Benevent J, Lacroix I. Drug prescriptions in French pregnant women between 2015 and 2016: a study in the EGB database. Therapie. 2021;76(3):239-47.

8. Centre de référence sur les agents tératogènes chez la femme enceinte (CRAT). https://www.lecrat.fr/. Accessed 1 Jun 2021.

9. Bumps-best use of medicine in pregnancy. https://medicinesinpreg nancy.org/. Accessed 1 Jun 2021.

10. Addis A, Sharabi S, Bonati M. Risk classification systems for drug use during pregnancy: are they a reliable source of information? Drug Saf. 2000;23:245-53.

11. Beyens M-N, Guy C, Ratrema M, Ollagnier M. Prescription of drugs to pregnant women in France: the HIMAGE study. Therapie. 2003;58:505-11.
12. Berthier M, Bonneau D, Perault MC, Oriot D, Chabot F, Maillauchaud MC, et al. Medications exposure during pregnancy. A study in a university hospital. Therapie. 1993;48:43-6.

13. Lacroix I, Damase-Michel C, Lapeyre-Mestre M, Montastruc JL. Prescription of drugs during pregnancy in France. Lancet. 2000;356:1735-6.

14. Trønnes JN, Lupattelli A, Nordeng H. Safety profile of medication used during pregnancy: results of a multinational European study. Pharmacoepidemiol Drug Saf. 2017;26:802-11.

15. Bezin J, Duong M, Lassalle R, Droz C, Pariente A, Blin P, et al. The national healthcare system claims databases in France, SNIIRAM and EGB: powerful tools for pharmacoepidemiology. Pharmacoepidemiol Drug Saf. 2017;26:954-62.

16. Raguideau F, Mezzarobba M, Zureik M, Weill A, Ricordeau P, Alla F. Compliance with pregnancy prevention plan recommendations in 8672 French women of childbearing potential exposed to acitretin. Pharmacoepidemiol Drug Saf. 2015;24:526-33.

17. Luu M, Benzenine E, Doret M, Michiels C, Barkun A, Degand T, et al. Continuous Anti-TNF $\alpha$ use throughout pregnancy: possible complications for the mother but not for the fetus. A retrospective cohort on the French national health insurance database (EVASION). Am J Gastroenterol. 2018;113:1669-77.

18. Blotière P-O, Miranda S, Weill A, Mikaeloff Y, Peyre H, Ramus F, et al. Risk of early neurodevelopmental outcomes associated with prenatal exposure to the antiepileptic drugs most commonly used during pregnancy: a French nationwide population-based cohort study. BMJ Open. 2020;10:e034829.

19. Blotière $\mathrm{P}-\mathrm{O}$, Weill $\mathrm{A}$, Dalichampt $\mathrm{M}$, Billionnet $\mathrm{C}$, Mezzarobba M, Raguideau F, et al. Development of an algorithm to identify pregnancy episodes and related outcomes in health care claims databases: an application to antiepileptic drug use in 4.9 million pregnant women in France. Pharmacoepidemiol Drug Saf. 2018;27:763-70.

20. Andrade SE, Raebel MA, Morse AN, Davis RL, Chan KA, Finkelstein JA, et al. Use of prescription medications with a potential for fetal harm among pregnant women. Pharmacoepidemiol Drug Saf. 2006;15:546-54.

21. Charlton BM, Mølgaard-Nielsen D, Svanström H, Wohlfahrt J, Pasternak B, Melbye M. Maternal use of oral contraceptives and risk of birth defects in Denmark: prospective, nationwide cohort study. BMJ. 2016;352:h6712.

22. Waller DK, Gallaway MS, Taylor LG, Ramadhani TA, Canfield MA, Scheuerle A, et al. Use of oral contraceptives in pregnancy and major structural birth defects in offspring. Epidemiology. 2010;21:232-9.

23. Jellesen R, Strandberg-Larsen K, Jørgensen T, Olsen J, Thulstrup AM, Andersen A-MN. Maternal use of oral contraceptives and risk of fetal death. Paediatr Perinat Epidemiol. 2008;22:334-40.

24. Ministère des affaires sociale et de la santé. Base de données publique des médicaments. http://base-donnees-publique.medic aments.gouv.fr/. Accessed 3 Jan 2020.

25. European Medicines Agency (EMA). Guideline on risk assessment of medicinal products on human reproduction and lactation: from data to labelling. 2008. https://www.ema.europa.eu/en/ documents/scientific-guideline/guideline-risk-assessment-medic inal-products-human-reproduction-lactation-data-labelling_en. pdf. Accessed 17 Aug 2021.

26. Eléfant E, Hanin C, Cohen D. Pregnant women, prescription, and fetal risk. Handb Clin Neurol. 2020;173:377-89.

27. Malm H, Martikainen J, Klaukka T, Neuvonen PJ. Prescription of hazardous drugs during pregnancy. Drug Saf. 2004;27:899-908.

28. Riley EH, Fuentes-Afflick E, Jackson RA, Escobar GJ, Brawarsky $\mathrm{P}$, Schreiber M, et al. Correlates of prescription drug use during pregnancy. J Womens Health (Larchmt). 2005;14:401-9.

29. Bakker MK, Jentink J, Vroom F, Van Den Berg PB, De Walle HEK, De Jong-Van Den Berg LTW. Drug prescription 
patterns before, during and after pregnancy for chronic, occasional and pregnancy-related drugs in the Netherlands. BJOG. 2006;113:559-68.

30. Gagne JJ, Maio V, Berghella V, Louis DZ, Gonnella JS. Prescription drug use during pregnancy: a population-based study in Regione Emilia-Romagna, Italy. Eur J Clin Pharmacol. 2008;64:1125-32.

31. Raichand S, Pearson S-A, Zoega H, Buckley NA, Havard A. Utilisation of teratogenic medicines before and during pregnancy in Australian women. Aust N Z J Obstet Gynaecol. 2020;60:218-24.

32. Engeland A, Bjørge T, Klungsøyr K, Hjellvik V, Skurtveit S, Furu $\mathrm{K}$. Trends in prescription drug use during pregnancy and postpartum in Norway, 2005 to 2015. Pharmacoepidemiol Drug Saf. 2018;27:995-1004.

33. van Gelder MMHJ, Bos JHJ, Roeleveld N, De Jong-Van Den Berg LTW. Drugs associated with teratogenic mechanisms. Part I: dispensing rates among pregnant women in the Netherlands, 1998-2009. Hum Reprod. 2014;29:161-7.

34. Stephansson O, Granath F, Svensson T, Haglund B, Ekbom A, Kieler H. Drug use during pregnancy in Sweden-assessed by the Prescribed Drug Register and the Medical Birth Register. Clin Epidemiol. 2011;3:43-50.

35. Yang T, Walker MC, Krewski D, Yang Q, Nimrod C, Garner P, et al. Maternal characteristics associated with pregnancy exposure to FDA category $\mathrm{C}, \mathrm{D}$, and $\mathrm{X}$ drugs in a Canadian population. Pharmacoepidemiol Drug Saf. 2008;17:270-7.

36. Lee E, Maneno MK, Smith L, Weiss SR, Zuckerman IH, Wutoh AK, et al. National patterns of medication use during pregnancy. Pharmacoepidemiol Drug Saf. 2006;15:537-45.

37. Marret H, Fauconnier A, Dubernard G, Misme H, Lagarce L, Lesavre $\mathrm{M}$, et al. Overview and guidelines of off-label use of methotrexate in ectopic pregnancy: report by CNGOF. Eur J Obstet Gynecol Reprod Biol. 2016;205:105-9.
38. Linet T. Surgical methods of abortion [in French]. J Gynecol Obstet Biol Reprod (Paris). 2016;45:1515-35.

39. Jackson E, Kapp N. Pain management for medical and surgical termination of pregnancy between 13 and 24 weeks of gestation: a systematic review. BJOG. 2020;127:1348-57.

40. Fiala C, Agostini A, Bombas T, Cameron S, Lertxundi R, Lubusky $\mathrm{M}$, et al. Management of pain associated with up-to-9-weeks medical termination of pregnancy (MToP) using mifepristonemisoprostol regimens: expert consensus based on a systematic literature review. J Obstet Gynaecol. 2020;40:591-601.

41. Olesen C, Sørensen HT, De Jong-Van Den Berg L, Olsen J, Steffensen FH, The Euromap Group. Prescribing during pregnancy and lactation with reference to the Swedish classification system. A population-based study among Danish women. Acta Obstet Gynecol Scand. 1999;78:686-92.

42. Cooper WO, Hickson GB, Ray WA. Prescriptions for contraindicated category $\mathrm{X}$ drugs in pregnancy among women enrolled in TennCare. Paediatr Perinat Epidemiol. 2004;18:106-11.

43. Feibus KB. FDA's proposed rule for pregnancy and lactation labeling: improving maternal child health through well-informed medicine use. J Med Toxicol. 2008;4:284-8.

44. Public Affairs Committee of the Teratology Society. Teratology public affairs committee position paper: pregnancy labeling for prescription drugs: Ten years later. Birth Defects Res Part A Clin Mol Teratol. 2007;79:627-30.

45. Wuytack F, Smith V, Cleary BJ. Oral non-steroidal antiinflammatory drugs (single dose) for perineal pain in the early postpartum period. Cochrane Database Syst Rev. 2016; Jul 14;7(7):CD011352. https://doi.org/10.1002/14651858.CD011 352.pub2. 